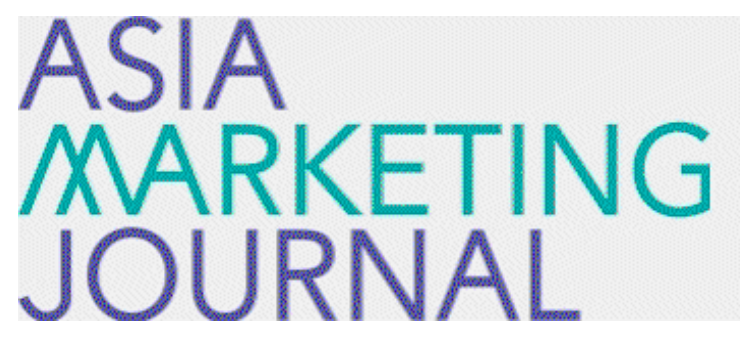

ASIA MARKETING JOURNAL

Volume 15 | Issue 2

Article 6

7-30-2013

\title{
From Thinking to Action
}

Dong Won Min

Hyun Mo Kang

Follow this and additional works at: https://amj.kma.re.kr/journal

Part of the Marketing Commons

\section{Recommended Citation}

Min, Dong Won and Kang, Hyun Mo (2013) "From Thinking to Action," Asia Marketing Journal: Vol. 15 : Iss. 2 , Article 6.

Available at: https://doi.org/10.53728/2765-6500.1521

This Article is brought to you for free and open access by Asia Marketing Journal. It has been accepted for inclusion in Asia Marketing Journal by an authorized editor of Asia Marketing Journal. 


\title{
From Thinking to Action: The Moderating Effect of Perspective Taking on Embodied Cognition*
}

\author{
Dongwon Min** \\ Hyunmo Kang***
}

Recent developments in embodied cognition suggest that people process environmental information by using their bodily state and mental simulation. The focus of embodiment theory is that cognitive processing is based on the interaction among the body, the mind, and the world. Based on embodied theories of cognition, the authors predict that when the representation of marathon running is activated, bodily feedback such as tiredness and thirst will occur because mental simulation of marathon running contains sensorimotor representation of marathon running. As a result, it is predicted that participants primed with marathon runner will have more desire to have products that enable thirsty-quenching. Specifically, this research proposes that consumers tendency to adopt the perspective of others influences embodied cognition, since perspective taking leads people to assimilate their own selfjudgments and behaviors toward the cognitive representations of others. An experiment reveals that both perceptual and cognitive perspective taking tendencies moderate how participants respond to the contextual cues. The effect of perspective taking is moderated by whether participants are prompted to adopt a first-person view or a third-person view. In detail, among the high perspective takers, those in the marathon-first-person condition drink more the mineral water than those in the marathonthird-person condition, who in turn drink more the mineral water than those in the control condition. Among the low perceptual perspective takers, however, there are no significant differences in the amount of mineral water intake.

This research delivers important insights for advertising messages. When being exposed to an advertisement, high perspective taking consumers may be more engaged in the advertised message than low perspective taking consumers, which in turn high (vs. low) perspective taking consumers' tendency to respond behaviorally consistent with the message may be higher. Based on the findings

\footnotetext{
* This work was supported by the National Research Foundation of Korea Grant funded by the Korean Government (NRF-2012S1A5A8023784)

** Assistant professor. Department of Business Administration. Dankook University (dwmin@dankook.ac.kr)

*** Assistant professor, Department of Business Administration, Kookmin University(hmkang@kookmin.ac.kr). Corresponding author
} 
of this research, if the message induces the high perspective taking consumers to have a first- (vs. third-) person view, this effect may be stronger. Moreover, if the advertising message contains behaviors, such as using the target product, inducing consumers to mimic the behaviors seems to bring more behavioral responses which marketers intend.

Key words: Embodied cognition. Mental simulation, Perceptual perspective taking, Cognitive perspective taking, First-person view, Third-person view

According to the viewpoint of embodied $\operatorname{cog}^{-}$ nition, knowledge is grounded in and consists of modality-specific representations which are used on cognitive processes, such as thinking and judgment (Barsalou, 1999). The theory argues that cognitive processes such as perception and memory are situated activities and deeply rooted in sensorimotor processing (Clark, 1997: Niedenthal et al., 2005). Thus, seeing an object or reading its name reenacts features (e.g., motion, action) that had become associated together. Specifically, embodiment theory has demonstrated that because cognition is situated (Bok and Min, 2013) and involves perception and action, cognition contributes to situation-appropriate behavior (Glenberg. 1997: Pfeifer and Scheier, 1999). More central to our research, literature on embodiment has proposed that motoric simulation plays a role in imitating, representing, and understanding behavior of other people. Consistently, findings in neuroscience demonstrated that mental simulation of one's own action and others actions involve similar brain area and computational processing (e.g., Decety and Sommerville, 2003: Lamm, Batson, and Decety, 2007).

Recently, Wilson (2002) distinguished between online and offline embodied cognition. The term 'online embodiment' refers to actual bodily state on real world environment. Online embodiment occurs in the presence of real external objects. In contrast, the term 'offline embodiment' refers "simulations of experience in the brain's modality-specific systems for perception, action, and introspection (Niedenthal et al., 2009, p. 184)." In this perspective, thinking about an action involves activation of the motor states that originally produced it because the body exerts a critical influence on forming one's cognitive representation (Barsalou, 2008: Glenberg. 1997: Malter, 1996). Related literature has argued that offline embodiment occurs during the use of perceptual symbols that refers to real stimuli not actually present (e.g., Barsalou, 1999). According to Wilson (2002), offline embodiment is body based and thinking about an object produces embodied states as if the object is actually there. 
Numerous findings have shown the evidence of both online and offline embodiment. Studies on online embodiment have shown that bodily responses during interaction with real objects affected behavioral responses, such that bodily postures and motor behavior were associated with positive and negative tendencies toward objects. For example, Wells and Petty (1980) showed that nodding one's head (vs, shaking it) affected one's level of agreement with a persuasive message, such that nodding the head led to more favorable attitudes toward the message content than shaking the head, Similarly, Tom et al. (1991) asked participants to nod or shake their heads and observed that nodding caused increased preference for a neutral object, whereas shaking resulted in a decline in preference for the neutral object. Consistent with this view, Strack, Martin, and Stepper (1988) showed that holding a pen between one's teeth (which facilitates a facial expressing during smiling) led to more favorable evaluation of cartoons than holding a pen between one's lip (which inhibits smiling). Also, using a conditioning conceptualization. Cacioppo, Priester, and Berntson (1993) found that neutral Chinese ideographs presented during arm flexion (approach action) were subsequently evaluated more favorably than ideographs presented during arm extension (avoidance action). More recently, research supported the concept of embodied cognition by showing that visual product depiction which facilitated more (vs. less) em- bodied mental simulation increased purchase intentions (Elder and Krishna, 2012).

According to offline embodiment approach. knowledge activates action schemas using modality-specific representations. Thus, priming abstract domains (e.g., time, justice, and love) influences how people perceive physical concepts tied to the body (e.g., Boroditsky and Ramscar, 2002). Consistently, findings supported the notion that cognition involves not only abstract mental representation but also sensorimotor schemas. For example, social exclusion induced an experience of feeling cold which in turn prompted greater desire for warm food and drink (Zhong and Leonardelli, 2008). In the Bargh, Chen, and Burrow (1996)'s study, participants in whom elderly stereotype had been primed subsequently walked down a hallway more slowly than did participants in whom the elderly stereotype had not been primed. Similarly, Chambon (2009) showed that after being primed with the elderly, participants estimated the gradient of various pathway and that of a hill steeper than non-primed participants.

The study we report in this research focused on offline embodied cognition. Based on previous literature, we predicted that when the representation of marathon running was activated, bodily feedback like thirst and tiredness would occur because mental simulation of marathon running contains sensorimotor representation of marathon running. As a result, it was predicted that participants primed with mar- 
athon runner would have more desire to have products that are beneficial for thirst-quenching or fatigue-recovery.

Interestingly, this research examined how embodied cognition was influenced by an individual difference - one's perspective taking tendency. Perspective taking is the ability to "read the minds" of other individuals. The ability to "see" things from someone else's perspective is considered to be the socio-cognitive abilities (Chandler 1973: Davis, 1983: Nurmsoo and Bloom, 2008). Flavell et al. (1968, p. 5) defined perspective taking as "that process in which the individual somehow cognizes $\cdots$ certain attributes of another person." Consistently. Epley and Caruso (2009, p. 299) described perspective taking as "everything from experiencing another person's emotion, to sympathizing with someone's experience, to anticipating another person's thoughts, to adopting another's visual perspective." One important implication of offline embodiment is that one's behaviors and judgments may assimilate toward the actions and mindset of others around them (Marx and Stapel, 2006: Wheeler and Petty, 2001). Consistently, Wheeler, DeMarree, and Petty (2007) observed that perspective taking moderated the effect of the overlap between a prime and the self on subsequent behavior. The fact is that offline embodiment is mental simulations of perceived actions and mindsets, which involves the process of imaginatively projecting oneself onto others' situation (Harris,
1992: Lee and Min, 2010). Hence, we predicted that the extent to which people mentally simulate actions and emotions would be influenced by their proclivity to adopt someone else's perspective. Most researchers distinguish between perceptual (sometimes referred to as visual, spatial or physical) perspective taking. cognitive (sometimes referred to as conceptual) perspective taking, and affective perspective taking (e.g., Epley, Caruso, and Bazerman, 2006: Farrant, Fletcher, and Maybery, 2006: Kurdek and Rodgon, 1975). While perceptual perspective taking is the ability to assume another person's visual, auditory or other perceptual viewpoint (Marvin, Greenberg, and Mossler, 1976), cognitive perspective taking refers to one's ability to intuit the knowledge, thoughts, attitudes and interests of another person (Chartrand and Bargh, 1999: Epley, Savitsky, and Gilovich, 2002: Savitsky, Epley, and Gilovich, 2002), and affective perspective taking is the ability to assess another person's emotional state, also known as empathy (Davis, 1983). Specifically, this research focused on perceptual perspective taking and the moderating effect of perceptual perspective taking on embodied cognition.

Research has shown that perspective taking often results in people assimilating their own self-judgments and behaviors toward the $\mathrm{cog}$ nitive representations they create of others (e.g.. Davis et al., 1996: Galinsky, Ku, and Wang, 2005: for a review, see Wheeler et al., 2007). For example, Chartrand and Bargh (1999) found 
that people who more readily adopt the perspectives of others were more likely to mimic others. Our view is that if people with a high perspective taking tendency are more likely to mentally simulate information they encounter, then they should be more influenced by contexts and advertising messages in their judgments and behaviors as compared to those with a low perspective taking tendency. We tested our hypothesis in a study by presenting participants with information on images of marathon races from start to finish to prime participants with the marathon-runner category. Based on previous findings, we predicted that high perspective taking participants exposed to marathon runners would be more likely than those in the control condition to mentally simulate the behaviors of someone running the marathon and simulate the situation of marathon running, and that, subsequently, their needs for the products that are conducive to achieving their thirst-quenching or fatigue-recovery goals would be higher.

To measure participants perceptual perspective taking, we asked them to mimic a yoga posture which was used in Lee and Min (2010. see Appendix). More specifically, we presented participants with a picture of a woman standing in a yoga posture with her right knee bent and asked them to demonstrate the same posture. It was expected that the attention of the high perceptual perspective takers would be directed outward toward the woman in the picture, resulting in a posture that resembles the image with their right knee bent: whereas the low perceptual perspective takers would be taking the more self-focused visual perspective of "an external observer looking back at oneself (Hass, 1984, p. 789)," resulting in a posture of bending their left knee instead. Thus, perceptual perspective taking is gauged by whether participants demonstrated the same (high perspective taking) or reflected (low perspective taking) yoga posture as the one in the picture.

Previous studies have suggested that a firstperson view could lead individuals to experience the similar self-representations as those the target (Davis et al., 1996: Regan and Totten, 1975: Smith and Henry, 1996: Wheeler, DeMarree, and Petty, 2005). Consistently, their findings showed that priming was stronger when participants adopted a first-person than third-person view (e.g., Marx and Stapel, 2006: Wheeler et al., 2001). To test the relationship between offline embodiment and perspective taking more clearly and moderating role of referencing (first- vs, third-person view) on our predicted effects, we prompted participants to adopt either a first- or a third-person view while exposing them to pictures of marathon races or to pictures of landscapes. Our prediction was that high (vs. low) perspective takers would embody to a greater extent when they were prompted to adopt a first-person (vs. thirdperson) view. 


\section{Experiment}

\section{Method}

In the experiment, we used a 2 (perceptual perspective taking: high vs. low) $\times 3$ (referencing: marathon-first-person vs, marathon-third-person vs. control) design with the amount of mineral water intake being the dependent variable. A total of 95 undergraduates (51 females) from a large-size university in Korea participated in the study in exchange for monetary compensation. The experiment was run in a computer lab using Qualtrics program. Before starting each session of the experiment, we provided a $500 \mathrm{ml}$ bottled mineral water beside each monitor. Participants were randomly assigned to one of the three conditions and announced that after completing the survey, they could drink given mineral water as much as they want. Participants were then presented with either 20 pictures related to marathon races (marathon-first-person and marathon-third-person conditions) or landscapes (control condition). We adapted the procedure for manipulating each condition from Lee and Min (2010, Experiments 2 and 3): Participants in the marathon-firstperson condition ( $\mathrm{N}=31,16$ females) read, "Please imagine that you have always wanted to run in a marathon. You follow all the major marathon events around the world, and have been training for a while. You are really look- ing forward to the event. Now imagine that you the runner have just crossed the finish line." Participants in the marathon-third-person condition ( $\mathrm{N}=34,19$ females) received the same message except that "you" was changed to "your friend." Participants in the control condition ( $\mathrm{N}$ $=30,16$ females) were instructed that they would be seeing pictures of landscapes. In this research, we were interested in the relationship between perception and cognition of physical concepts. To investigate whether perceptual perspective taking and cognitive perspective taking are highly correlated with each other, we measured participants' cognitive perspective taking tendency using the 7-item perspectivetaking subscale (e.g., "I sometimes try to understand my friends better by imagining how things look from their perspective," "I try to look at everybody's side of a disagreement before I make a decision." "I believe that there are two sides to every question and try to look at them both.") of the Interpersonal Reactivity Index (Davis, 1980). To rule out possible alternative interpretations of our effect tied to mood, participants reported how they felt (happy. anxious, relaxed, energized, irritated, sad, elated, contented) using 7-points scales ( $1=$ not at all, $7=$ a lot). They then responded to some miscellaneous questions such as gender and handedness. Upon completion of the questionnaire, participants were led out of the computer lab individually. Before they left, they were instructed that they should put the bottle 
of mineral water on the desk. Once outside the lab, they were presented with the picture of a woman in a yoga posture which was used in Lee and Min (2010) to measure participants' perceptual perspective tendency. Participants were then asked to demonstrate the same posture, supposedly to assess how good their balance was. Participants' posture (same or reflected) was recorded to measure their perceptual perspective taking. Finally, participants were thanked, debriefed, and dismissed. At the end of each session, an experimenter measured the amount of mineral water intake using a beaker.

\section{Results}

Forty-seven of the 95 participants adopted the same posture as in the picture: they were classified as high perceptual perspective takers. The results of a logistic regression showed that participants' yoga posture orientation $(1=$ same, 0 = otherwise) did not differ based on their affective states, gender, and handedness (68 right-handed and 27 left-handed), $p s>.20$.

The results of a 2 (perceptual perspective taking) $\times 3$ (referencing) analysis of variance (ANOVA) with the amount of mineral water intake as a dependent variable showed that the main effect of perceptual perspective taking was significant $(\mathrm{F}(1,89)=130.37, p<.001)$, showing that high perceptual perspective takers drank more of the mineral water than did low perceptual perspective takers $\left(M_{\text {high }}=\right.$ $390.08_{\mathrm{m},}, \mathrm{SD}=81.98$ vs. $\mathrm{M}_{\mathrm{low}}=247.47_{\mathrm{m}}, \mathrm{SD}$ $=62.86)$. The main effect of referencing was significant $(F(1,89)=16.54, p<.001)$. Planned contrast confirmed that the amount of mineral water intake between participants in the marathon-first-person condition $(\mathrm{M}=$ $\left.340.99_{\mathrm{m}}, \mathrm{SD}=130.67\right)$ and those in the marathon-third-person condition $\left(\mathrm{M}=346.62_{\mathrm{m}}\right.$, $\mathrm{SD}=70.89)$ was not significantly different ( $\mathrm{t}$ (1), however, the amount of mineral water intake in the control condition ( $\mathrm{M}=261.88_{\mathrm{m} \text {, }}$, $\mathrm{SD}=74.52$ ) was significantly less than that in the marathon-third-person condition $(\mathrm{t}(89)=$ 5.97, $p<.001)$. The Perceptual perspective taking $\times$ Referencing was also significant $(\mathrm{F}(2$. $89)=19.74, p$ (.001). Separate analyses were conducted for the participants' perspective taking tendency. As illustrated in Figure 1, among the high perceptual perspective takers, those in the marathon-first-person condition drank more of the mineral water $\left(\mathrm{M}=463.52_{\mathrm{m}}, \mathrm{SD}=\right.$ 42.10) than those in the marathon-third-person condition $\left(\mathrm{M}=389.29_{\mathrm{m} .} . \mathrm{SD}=43.20: \mathrm{t}(89)=\right.$ $3.83, p<.001$ ), who in turn drank more than those in the control condition $\left(\mathrm{M}=299.58_{\mathrm{ml}}\right.$, $\mathrm{SD}=79.59: \mathrm{t}(89)=4.33, p<.001)$. Among the low perceptual perspective takers, however, we did not find any significant difference. In detail, there was no difference in the amount of mineral water intake between those in the marathon-first-person condition ( $\mathrm{M}=273.88_{\mathrm{m} \text { l. }}$. $\mathrm{SD}=58.33)$ and those in the marathon-thirdperson condition $\left(\mathrm{M}=285.66_{\mathrm{m},}, \mathrm{SD}=56.81\right.$ : 
$\mathrm{t}(89)=1.28, p>10)$. Low perspective takers' amount of mineral water intake did not differ between those in the marathon-third-person and the control conditions $\left(\mathrm{M}=279.75_{\mathrm{m}}\right.$, SD $=60.85: t<1)$. Finally, the amount of mineral water intake between those in the marathonfirst-person and the control conditions did not differ $(\mathrm{t}(89)=1.57, p>.10)$.

To test whether the measurement of perceptual perspective taking was enough to explain participants' cognitive perspective taking tendency, we examined the relationship between participants' perceptual and cognitive perspective taking. For this, we created a cognitive perspective taking index by averaging the seven items $(a=.95)$. Not surprisingly, a regression analysis showed a positive effect of perceptual perspective taking on cognitive perspective taking $(\beta=1.98, \mathrm{SE}=.17, \mathrm{t}(93)=11.94, p$ $<.001)$. Subsequent analyses showed that condition had no effect on perceptual perspective taking $\left(X^{2}<1\right)$ or cognitive perspective taking $(F<1)$, suggesting that the three conditions had equivalent numbers of high and low perspective takers. Further, participants' affective states, gender, and handedness did not differ among the three conditions, $p s>.10$.

To investigate whether there were substantial differences when cognitive perspective taking was used instead of perceptual perspective taking, we next examined the effect of cognitive perspective taking. Firstly, we categorized participants as high and low cognitive perspective takers based on a median split of the cognitive perspective taking index. The results of a 2 (cognitive perspective taking) $\times 3$ (re-

〈Figure 1〉 The Effect of Perceptual Perspective Taking and Referencing

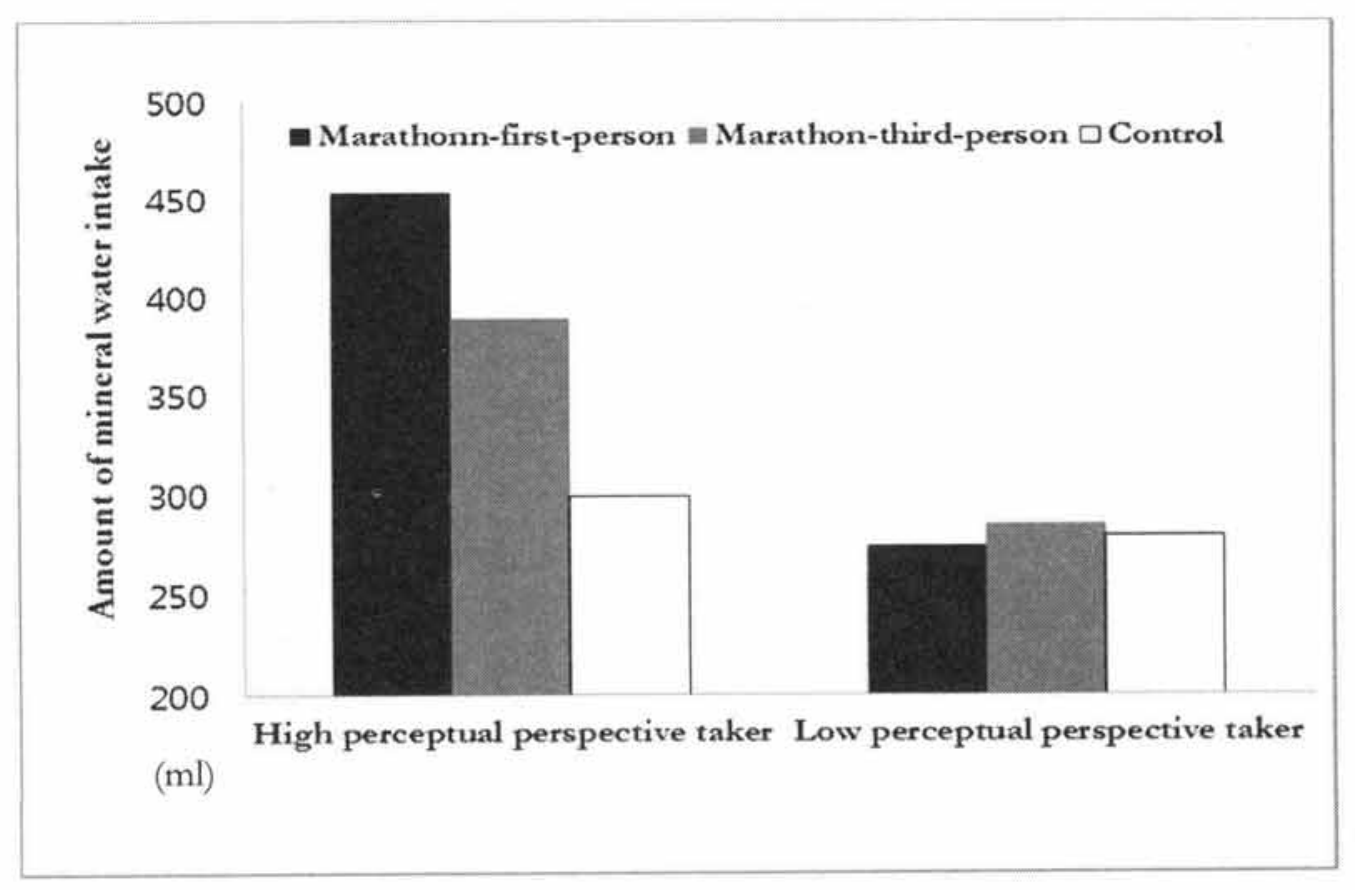


ferencing) ANOVA with the amount of mineral water intake being a dependent variable showed very similar patterns of data as did the results of a 2 (perceptual perspective taking) $x$ 3 (referencing) ANOVA. The main effect of cognitive perspective taking was significant $(\mathrm{F}(1,89)=54.94, p<.001)$, showing that high cognitive perspective takers left less the mineral water than low cognitive perspective takers $\left(\mathrm{M}_{\text {high }}=377.76_{\mathrm{ml}}, \mathrm{SD}=86.26\right.$ vs. $\mathrm{M}_{\mathrm{low}}$ $\left.=264.26_{\mathrm{m}}, \mathrm{SD}=83.94\right)$. The main effect of referencing was significant $(F 2,89)=14,57, p$ $<$.001). Planned contrast confirmed that the amount of mineral water intake between participants in the marathon-first-person condition $\left(\mathrm{M}=340.99_{\mathrm{m}}, \mathrm{SD}=130.67\right)$ and those in the marathon-third-person condition ( $\mathrm{M}=346.62_{\mathrm{m}}$, $\mathrm{SD}=70.89)$ did not show a significant differ- ence $(t<1)$. However, the amount of mineral water intake in the control condition $(\mathrm{M}=$ $261.88_{\mathrm{m}}$. SD $=74.52$ ) was significantly less than the amount of mineral water intake in the marathon-third-person condition $(t(89)=$ 4.66, $p<.001$ ). More importantly, the effect of Cognitive perspective taking $\times$ Referencing was significant $(\mathrm{F}(2,89)=7.90, p<.005)$. Follow-on contrasts showed that among the high cognitive perspective takers, those in the marathon-first-person condition drank more the mineral water $\left(\mathrm{M}=458.33_{\mathrm{m} m} . \mathrm{SD}=\right.$ 45.56) than those in the marathon- third-person condition $\left(\mathrm{M}=389.29_{\mathrm{m} l}, \mathrm{SD}=43.20\right.$; $\mathrm{t}(89)=2.61, p<.001)$, who in turn drank more the mineral water than those in the control condition $\left(\mathrm{M}=285.66_{\mathrm{m}}, \mathrm{SD}=80.78\right.$ : $\mathrm{t}(89)=4.01, p<.001)$. Among the low cogni-

〈Figure 2〉 The Effect of Cognitive Perspective Taking and Referencing

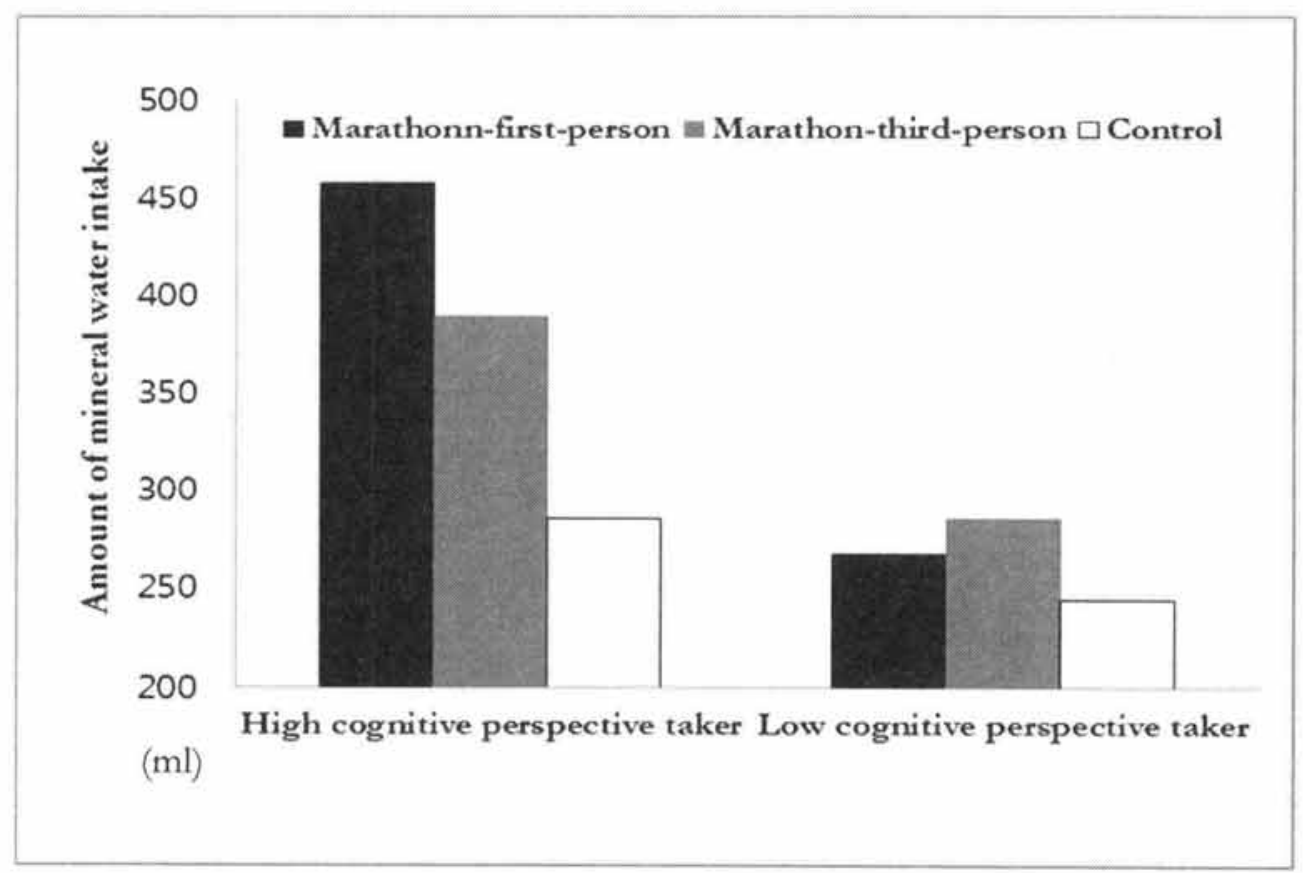

From Thinking to Action: The Moderating Effect of Perspective Taking on Embodied Cognition 125 
tive perspective takers, participants across three conditions did not differ in the amount of mineral water intake $\left(\mathrm{M}_{\text {first }}=266.88_{\mathrm{m}}, \mathrm{SD}=\right.$ 110.50 vs. $\mathrm{M}_{\text {third }}=285.66_{\mathrm{mll}} . \mathrm{SD}=56.81$ vs. $\mathrm{M}_{\text {control }}=243.70_{\mathrm{m},}, \mathrm{SD}=66.04: p \mathrm{~s}\langle .10)$. The results are illustrated in Figure 2.

\section{General Discussion}

Prior studies demonstrated that embodied $\operatorname{cog}$ nition affects cognitive representation (Barsalou, 2008: Glenberg, 1997), judgment (Briñol and Petty, 2008: Chambon, 2009), choice, purchase intention (Elder and Krishna, 2012: Rosa, Garbarino, and Malter, 2006), purchase behavior (Thompson, Locander, and Pollio, 1990), and emotional response (Dimberg, Thunberg, and Elmehed, 2000; Hawk, Fischer, and Van Kleef. 2012). In this research, we show that priming of marathon running increases desire for mineral water. Importantly, this process is moderated by participants' perspective taking tendency, such that participants embody more when they are more inclined to perceptually take on another person's perspective. This effect is also found when participants has stronger tendency to take others' perspective cognitively. Our study also shows that high perspective takers embody to a greater extent when they are asked to adopt the first-person rather than third-person view. Hence, the findings general- ize the results of prior research which reveal the moderating effect of referencing on embodied stereotyping, such that people writing in first- (vs. third-) person become more stereotyped, and exhibit more stereotype-consistent behaviors (e.g., Marx and Stapel, 2005).

This research has a contribution to consumer research by introducing embodied cognition as an alternative framework to the traditional structural model of memory and cognition to understanding how consumer interacts with environment in their judgment and action. Although the traditional amodal models have demonstrated that the mind is separated from and operates independently of the body (for review, see Haney, 2002), our results are more consistent with the embodiment model that the mind and the body are integrated. When participants are exposed to images of marathon races, they desire mineral water more, providing evidence that the body is an integral part of an inseparable mind-body whole.

This research contributes to the literature on embodied cognition in several ways. First, it identifies one's perspective taking tendency as an important moderator of embodiment. Second, this study offers one way to measure people's perceptual perspective taking proclivity. Third, it establishes the moderating effect of referencing on the relationship between embodiment and perspective taking.

According to embodied cognition theories, online cognition occurs in the presence of actual 
stimuli, whereas offline cognition occurs then the perceiver represent objects in their absence (Wilson, 2002). In this research, our interests are on offline embodiment and the similarity in the moderating effect of perceptual and cognitive perspective taking on embodiment. Can our results be obtained with online embodiment? In the view of online embodied cognition, bodily responses during interaction with objects influence later-reported attitudes and action tendencies toward the objects. Thus, it is possible that perceptual perspective taking is more sensitive measure than self-reported cognitive perspective taking in online embodiment since perceptual perspective taking operates directly on bodily states. Investigation of this premise awaits further research.

This research further delivers important insights for advertising messages. When being exposed to an advertisement, high perspective taking consumers may be more engaged in the advertised message than low perspective taking consumers, which in turn high (vs. low) perspective taking consumers' tendency to respond behaviorally consistent with the message may be higher. Based on the findings of this research, if the message induces the high perspective taking consumers to have a first- (vs. third-) person view, this effect may be stronger. However, if consumers are low perspective takers, the effect of referencing may not be found. Precious studies have suggested that mimic behavior increases one's perspective taking tendency. Therefore, if the advertising message contains behaviors, such as using the target product, inducing consumers to mimic the behaviors seems to bring more behavioral responses which marketers intend.

Recent social psychology literature demonstrates that psychological power decreases the tendency to take other's perspective (e.g., Galinsky et al., 2006). Many companies often phrases such as "the customer is always right" and "the customer is king" to convey their eagerness to put their customers first, which in turn make their customers feel special and powerful. However, as Former Continental Airlines CEO Gordon Bethune points out, the strategy of making customers feel powerful can induce unreasonable and intransigent behaviors (Bethune and Huler, 1998). This result could come from perceptually powerful customers' reduced tendency to take the corporates' perspective. With this issue, Min and Kim (2012, 2013)'s suggestion that "firms should augment their customers' perceived power cautiously. Therefore, instead of "the customer is always right," for example, the slogan "we address what you want before you ask" may slightly shift the center of power from the customer to the firm" seems to be helpful. We leave this issue to future empirical research.

〈Received January 17. 2013〉

〈1st Revised April 22. 2013〉

〈2nd Revised May 7. 2013〉

〈Accepted May 14. 2013〉 


\section{References}

Bargh, John A., Mark Chen, and Lora Burrows (1996), "Automaticity of Social Behavior: Direct Effects of Trait Construct and Stereotype Activation on Action," Journal of Personality and Social Psychology, 71 (8), 230-44.

Barsalou, Lawrence W. (2008), "Grounded Cognition," Annual Review of Psychology, 59 (1), 617-45.

Bok, Sang Y. and Dongwon Min (2013), "The Effect of Emotional Certainty on Attitudes in Advertising," Asia Marketing Journal, 14 (4), 35-53.

Boroditsky, Lera and Michael L. Ramscar (2002), "The Roles of Body and Mind in Abstract Thought," Psychological Science, 13 (2), 185-88.

Briñol, Pablo and Richard E. Petty (2008), "Embodied Persuasion: Fundamental Processes by which Bodily Responses Can Impact Attitudes, in Embodiment Grounding: Social, Cognitive, Affective, and Neuroscientific Approaches, Gün R. Semin and Eliot R. Smith (eds.), Cambridge: Cambridge University Press, 184-207.

Cacioppo, John T., Joseph R. Priester, and Gary G. Berntson (1993), "Rudimentary Determinants of Attitudes. II: Arm Flexion and Extension Have Differential Effects on Attitudes," Journal of Personality and
Social Psychology, 65 (1), 5-17. Chambon, Michel (2009), "Embodied Perceptions with Other's Bodies in Mind: Stereotype Priming Influence on the Perception of Spatial Environment," Journal of Experimental Social Psychology, 45 (1), 283-87. Chandler, Michael J. (1973), "Egocentrism and Antisocial Behavior: The Assessment and Training of Social Perspective-Taking Skills," Developmental Psychology, 9 (3), 326-32. Chartrand, Tanya L. and John A. Bargh (1999), "The Chameleon Effect: The PerceptionBehavior Link and Social Interaction," Journal of Personality and Social Psychology, 76 (6), 893-910.

Davis, Mark H. (1983), "Measuring Individual Differences in Empathy: Evidence for a Multidimensional Approach," Journal of Personality and Social Psychology, 44 (1), 113-26.

Davis, Mark H., Laura Conklin, Amy Smith, and Carol Luce (1996) "Effect of Perspective Taking on the Cognitive Representation of Persons: A Merging of Self and Other," Journal of Personality and Social Psychology, 70 (4), 713-26.

Decety, Jean, Marc Jeannerod, M. Germain, J. Pastene (1991), "Vegetative Response during Imagined Movement is Proportional to Mental Effort," Behavioral Brain Research, 42 (1), 1-5.

Decety, Jean, and Jessica A. Sommerville (2003), "Shared Representations between Self and 
Others: A Social Cognitive Neuroscience View," Trends in Cognitive Sciences, 7, 527-33.

Dijksterhuis, Ap and John A. Bargh (2001), "The Perception-Behavior Expressway: $\mathrm{Au}^{-}$ tomatic Effects of Social Perception and Social Behavior," in Advances in Experimental Social Psychology, Vol. 30, Mark P. Zanna (ed.), NY: Academic Press, 1-40. Dimberg, Ulf, Monika Thunberg, and Kurt Elmehed (2000), "Unconscious Facial Reactions to Emotional Facial Expressions," Psychological Science, 11 (1), 86-9.

Elder, Ryan S. and Aradhna Krishna (2012), "The 'Visual Depiction Effect' in Advertising: Facilitating Embodied Mental Simulation Through Product Orientation," Journal of Consumer Research, 38 (6), 9881003.

Epley Nicholas and Eugene M. Caruso (2009), "Perspective Taking: Misstepping into Others' Shoes," in The Handbook of Imagination and Mental Simulation, Keith D. Markman, William M.P. Klein, and Julie A. Suhr (eds.). New York: Psychology Press, 295-309.

Epley, Nicholas, Kenneth Savitsky, and Thomas Gilovich (2002), "Empathy Neglect: $\mathrm{Re}^{-}$ conciling the Spotlight Effect and the Correspondence Bias," Journal of Personality and Social Psychology, 83 (2), 300-12.

Farrant, Brad M., Janet Fletcher, and Murray T. Maybery (2006), "Specific Language Impairment, Theory of Mind, and Visual Perspective Taking: Evidence for Simula- tion Theory and the Developmental Role of Language," Child Development, 77 (5), 1842-53.

Flavell, John, Charles L. Fry, JR., John W. Wright, and Paul E. Jarvis (1968), The Development of Role Taking and Communication Skills in Children, NY: Wiley.

Galinsky, Adam D. Gillian Ku, and Cynthia S. Wang (2005), "Perspective-Taking and SelfOther Overlap: Fostering Social Bonds and Facilitating Social Coordination," Group Processes and Intergroup Relations, 8 (2). 109-24.

Glenberg, Arthur M. (1997), "What Memory Is for: Creating Meaning in the Service of Action," Behavioral and Brain Science, 20 (1), 41-50.

Haney, William S. (2002), Culture and Consciousness: Literature Regained, PA: Bucknell University Press.

Harris, Paul L. (1992), "From Simulation to Folk Psychology: The Case for Development," Mind and Language. 7 (3), 120-44.

Hass, R.Glen (1984), "Perspective Taking and Self-awareness: Drawing an E on Your Forehead," Journal of Personality and Social Psychology, 46 (4), 788-98.

Hawk, Skyler T., Agneta H. Fischer, and Gerben A. Van Kleef (2012), "Face the Noise: Embodied Responses to Nonverbal Vocalizations of Discrete Emotions," Journal of Personality and Social Psychology, 102 (4), 796-814. 
Jeannerod, Marc (1994), "The Representing Brain:

Neural Correlates of Motor Intention and Imagery," Behavioral and Brain Sciences, 17 (2), 187-245.

Jeannerod, Marc (1997), The Cognitive Neuroscience of Action, Oxford: Blackwell.

Kurdek, Lawrence A. and Maris M. Rodgon (1975), "Perceptual, Cognitive, and Affective Perspective Taking in Kindergarten through Sixth-Grade Children," Developmental Psychology, 11 (3), 643-50.

Lamm, Claus, C. Daniel Batson, and Jean Decety (2007), "The Neural Substrate of Human Empathy: Effects of Perspectivetaking and Cognitive Appraisal," Journal of Cognitive Neuroscience, 19 (1), 42-58.

Lee, Angela Y. and Dongwon Min (2010), "Perspective Taking and Embodiment," in Proceedings of Annual Conference of the Association for Consumer Research, A. Labroo \& A. Y. Lee (Eds.), Jacksonville, Fl. Lee, Spike W. S. and Norbert Schwarz (2010), "Dirty Hands and Dirty Mouths: Embodiment of the Moral-Purity Metaphor Is Specific to the Motor Modality Involved in Moral Transgression," Psychological Science, 21 (10), 1423-25.

Malter, Alan J. (1996), “An Introduction to Embodied Cognition: Implications For Consumer Research", in Advances in Consumer Research, Vol, 23, Kim P. Corfman and John G. Lynch Jr, (eds.), 272-76.

Marvin, Robert S., Mark T. Greenberg, and
Daniel G. Mossler (1976), "The Early Development of Conceptual Perspective Taking: Distinguishing among Multiple Perspectives," Child Development, 47 (2), 511-14.

Marx, David M. and Diederik A. Stapel (2006). "It Depends on Your Perspective: The Role of Self-Relevance in Stereotype-Based Underperformance," Journal of Experimental Social Psychology, 42 (11), 768-75.

Min, Dongwon and Kim, Ji-Hern (2012), "The Effect of Psychological Power on Stereotyping of Brand Extended Product," Korean Journal of Advertising, 23 (7), 35-61.

Min, Dongwon and Kim, Ji-Hern (2013), "Is Power Powerful? Power, Confidence, and Goal Pursuit," International Journal of Research in Marketing, 30 (3), 265-75.

Niedenthal, Paula M., Lawrence W. Barsalou, Piotr Winkielman, Silvia Krauth-Gruber, and François Ric (2005), "Embodiment in Attitudes, Social Perception, and Emotion," Personality and Social Psychology Review, 9 (3), 184-211.

Niedenthal, Paula M., Piotr Winkielman, Laurie Mondillon, and Nicolas Vermeulen (2009), "Embodied Emotion Concepts," Journal of Personality and Social Psychology, 96 (6), 1120-36.

Nurmsoo, Erika and Paul Bloom, "Preschoolers' Perspective Taking in Word Learning: Do They Blindly Follow Eye Gaze?" Psychological Science, 19 (3), 211-15.

Pfeifer, Rolf and Christian Scheier (1999), Un- 
derstanding Intelligence, Cambridge, MA: MIT Press.

Regan, Dennis T. and Judith D. Totten (1975), "Empathy and Attribution: Turning Observers into Actors," Journal of Personality and Social Psychology, 32 (5), 850-56.

Rosa, José Antonio, Ellen C. Garbarino, and Alan J. Malter (2006), "Keeping the Body in Mind: The Influence of Body Esteem and Body Boundary Aberration on Consumer Beliefs and Purchase Intentions," Journal of Consumer Psychology, 16, 79-91.

Savitsky, Kenneth, Nicholas Epley, and Thomas Gilovich (2001), "Is It as Bad as We Fear?: Overestimating the Extremity of Others' Judgments," Journal of Personality and Social Psychology, 81 (1), 44-56.

Schubert, Thomas W. (2005), "Your Highness: Vertical Positions as Perceptual Symbols of Power," Journal of Personality and Social Psychology, 89 (1), 1-21.

Smith, Eliot R. and Susan Henry (1996), "An In-group Becomes Part of the Self: $\mathrm{Re}^{-}$ sponse Time Evidence," Personality amd Social Psychology Bulletin, 22 (6), 635-42. Strack, Fritz, Leonard L. Martin, and Sabine Stepper (1988), "Inhibiting and Facilitating Conditions of the Human Smile: A NonObtrusive Test of the Facial Feedback Hypothesis," Journal of Personality and Social Psychology, 54 (5), 768-77.

Tom, Gail, Paul Pettersen, Teresa Lau, Trevor Burton, and Jim Cook (1991), "The Role of
Overt Head Movement in the Formation of Affect," Basic and Applied Social Psychology, 12 (3), 281-89.

Thompson, Craig J., William B. Locander, and Howard R. Pollio (1990), "The Lived Meaning of Free Choice: An ExistentialPhenomenological Description of Everyday Consumer Experiences of Contemporary Married Women," Journal of Consumer Research, 17 (3), 346-61.

Wells, Gary L. and Richard E. Petty (1980), "The Effects of Over Head Movements on Persuasion: Compatibility and Incompatibility of Responses," Basic and Applied Social Psychology, 1 (3), 219-30.

Wheeler, S. Christian, Kenneth G. DeMarree, and Richard E. Petty (2007), "Understanding the Role of the Self in Prime-to-Behavior Effects: The Active-Self Account," Personality and Social Psychology Review, 11 (3), 234-61.

Wheeler, S. Christian and Richard E. Petty (2001), "The Effects of Stereotype Activation on Behavior: A Review of Possible Mechanisms," Psychological Bulletin, 127 (6), 797-826.

Wilson, Margaret (2002), "Six Views of Embodied Cognition," Psychonomic Bulletin and Review, 9 (4), 625-36.

Zhong. Chen-Bo and Geoffrey J. Leonardelli (2008), "Cold and Lonely: Does Social Exclusion Literally Feel Cold?" Psychological Science, 19 (9), 838-42. 


\section{$\langle$ APPENDIX〉}

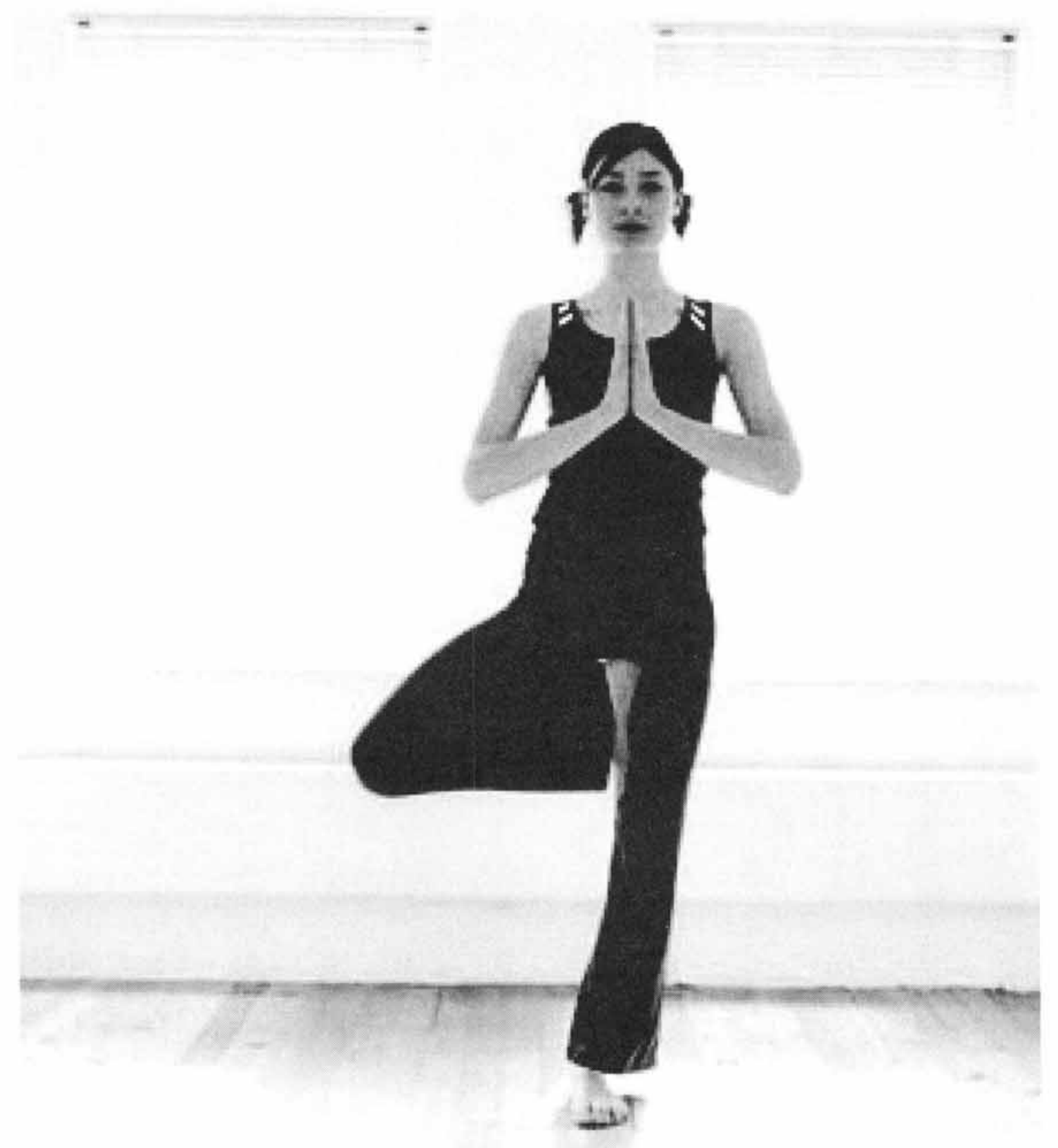

132 ASIA MARKETING JOURNAL Vol. 15 No. 02 July 2013 